University of Wollongong

Research Online

Faculty of Arts, Social Sciences and Humanities

- Papers

Faculty of Arts, Social Sciences \& Humanities

2019

Exploring the Development and Research Focus of Cognitive Load Theory, as Described by Its Founders: Interviewing John Sweller, Fred Paas, and Jeroen van Merriënboer

Myrto-Foteini Mavilidi

University Of Newcastle,mfm351@uowmail.edu.au

Lijia Zhong

Hangzhou Normal University

Follow this and additional works at: https://ro.uow.edu.au/asshpapers

Research Online is the open access institutional repository for the University of Wollongong. For further information contact the UOW Library: research-pubs@uow.edu.au 


\title{
Exploring the Development and Research Focus of Cognitive Load Theory, as Described by Its Founders: Interviewing John Sweller, Fred Paas, and Jeroen van Merriënboer
}

\author{
Abstract \\ This manuscript presents an interview with John Sweller, Fred Paas, and Jeroen van Merrienboer about \\ cognitive load theory. It presents the views of these main founders of the theory on the progress from the \\ first major publication on the theory in 1998 (Sweller, Van Merrienboer, \& Paas, Educational Psychology \\ Review, 10(3), 251-296, 1998) to the current publication, 20 years later in 2018 (Sweller, Van Merrienboer, \\ \& Paas, Educational Psychology Review, https://doi.org/10.1007/s10648-019-09465-5, 2019). More \\ specifically, the interview focuses on challenges and opportunities of cognitive load theory and the \\ associated instructional design research, the role of measurement of cognitive load and mental efficiency, \\ as well as the instructional control of cognitive load in the cognitive load research. The interview is \\ concluded with suggestions and advice for young researchers.

\section{Publication Details} \\ Mavilidi, M. \& Zhong, L. (2019). Exploring the Development and Research Focus of Cognitive Load Theory, \\ as Described by Its Founders: Interviewing John Sweller, Fred Paas, and Jeroen van Merriënboer. \\ Educational Psychology Review, 31 (2), 499-508.
}


Exploring the development and research focus of cognitive load theory, as described by its founders: Interviewing John Sweller, Fred Paas, and Jeroen van

\title{
Merriënboer
}

\begin{abstract}
This manuscript presents an interview with John Sweller, Fred Paas, and Jeroen van Merrienboer about cognitive load theory. It presents the views of these main founders of the theory on the progress from the first major publication on the theory in 1998 (Sweller, Van Merrienboer, \& Paas, 1998) to the current publication, twenty years later in 2018 (Sweller, Van Merrienboer, \& Paas, 2019). More specifically, the interview focuses on challenges and opportunities of cognitive load theory and the associated instructional design research, the role of measurement of cognitive load and mental efficiency, as well as the instructional control of cognitive load in the cognitive load research. The interview is concluded with suggestions and advice for young researchers.
\end{abstract}

Keywords: cognitive load theory, interview, cognitive load measurement, advice for young researchers 


\section{Biographies}

John Sweller is Emeritus Professor of Educational Psychology in the School of Education, at the University of New South Wales. His research is associated with the cognitive load theory (CLT), an instructional theory based on our knowledge of human cognitive architecture. He initiated work on the theory in the early 1980's. Subsequently, "ownership" of the theory shifted to his research group at UNSW and then to a large group of international researchers. The theory is now a contributor to both research and debate on issues associated with human cognitive architecture, its links to evolution by natural selection, and the instructional design consequences that follow. It is one of the few theories to have generated a large range of novel instructional designs from our knowledge of human cognitive architecture. Based on any commonly used citation index, the work has been cited on over 15 thousand occasions.

Fred Paas is full Professor of Educational Psychology at Erasmus University Rotterdam, where he has served since 2004. He is also Professorial Fellow at the School of Education and Early Start at the University of Wollongong, Australia, and has been an Adjunct Professor at the School of Education of the University of New South Wales, Australia. He was identified as the world's most productive researcher in the five top journals in the field of Educational Psychology for 2009-2014 (Educational Psychology Review, 2016, Vol. 28, pp. 215-223). In 2010 he was selected as a Fellow of the American Educational Research Association. He serves as the editor-in-chief of the journal Educational Psychology Review from 2015-2021, and on the board of several other journals, such as the Journal of Educational Psychology and Educational 
Technology Research \& Development. For the past 25 years he has conducted research on CLT, complex learning and human movement.

Jeroen van Merriënboer is full Professor of Learning and Instruction and Research Director of the School of Health Professions Education (SHE) at Maastricht University, the Netherlands, where he served since 2009. His books Training Complex Cognitive Skills (1997) and Ten Steps to Complex Learning (3 ${ }^{\text {rd }}$ Edition published in 2018) had a major impact on the field of instructional design and have been translated in several languages. Van Merrienboer received numerous scientific awards for his research, both for his publications and for his international contributions. He was selected as a Fellow of the American Educational Research Association, he was associate editor of the journal Learning and Instruction (20092013), and he served on the editorial board of many other journals, including Computers in Human Behaviour; Educational Research Review, and Educational Technology, Research and Development. For the past 25 years, he has conducted research on CLT, four-component instructional design (4C/ID), and lifelong learning in the professions.

I. The challenge and opportunity in CLT research.

How did you become involved in CLT, complex learning and instructional design? 
John: Research about complex learning flowed easily from CLT. I was interested from the beginning in areas such as mathematics and science and these areas are intrinsically complex. Then I realised as data came in, that CLT could be easily applied to complex learning.

The biggest challenge for me has always been to convince people to take note of CLT. That has been a massive effort because in the early days when I was working on the worked-example effect, the whole field followed an ideology that we had to get people to learn to solve novel problems. That was a challenge. We are overcoming the objections to the use of worked examples now, over 30 years since the effect was demonstrated (Sweller \& Cooper, 1985).

Until literally 18 months ago, my assumption was that working memory was pretty much fixed for any given individual and was only changed by information in long-term memory. That view has changed now because we assume that if you are engaged in heavy cognitive effort, working memory is depleted (Chen, CastroAlonso, Paas, \& Sweller, 2018). This suggestion had previously never been part of CLT.

Fred: When I started as a PhD student in 1989, I was inspired by John Sweller's research and decided to focus my $\mathrm{PhD}$ project on CLT, which has resulted in my $\mathrm{PhD}$ thesis on 'Instructional control of cognitive load in the training of complex cognitive tasks'. In the beginning it was, and still is, a great challenge to find ways to further develop CLT. In my research, I tried to change this focus on decreasing the cognitive load by studying worked-out examples to optimally using the 
available cognitive capacity. This means that the capacity that is freed by using worked examples instruction can be used for other productive learning activities, such as studying a higher variety of worked examples (i.e., variability effect, see Paas \& Van Merriënboer, 1994). This also turned out to be the basis for the idea of germane cognitive load. Another idea was that CLT based instructional methods that deal effectively with working memory capacity should be particularly effective for people with a lower working memory capacity, such as older adults (Paas, Camp, \& Rikers, 2001).

Jeroen: I became interested in CLT in the 1980s, when I was doing my PhD research on teaching computer programming. It turned out that worked examples of real, meaningful computer programs were essential for learning computer programming (van Merriënboer \& Krammer, 1987). I also developed so-called completion assignments, where students had to finish incomplete computer programs (van Merriënboer, 1990; van Merriënboer \& de Croock, 1992). Thus, students had to carefully study a partial worked example of a real computer program and then complete it.

For me, the biggest challenge has always been the application of CLT principles to the design of courses and curricula. Direct applications of CLT are mostly on the level of instructional tasks, such as texts with pictures, educational videos, instructional animations and simulations, or other types of multimedia presentations. It is less easy to apply CLT to the design of lengthier educational programs, and therefore my research has always been concerned with two 
theoretical frameworks that are strongly interrelated: CLT and 4C/ID (fourcomponent instructional design; for the first publication on $4 \mathrm{C} / \mathrm{ID}$, see van Merriënboer, Jelsma, \& Paas, 1992). Both theories are based on the same assumptions about human cognitive architecture, but CLT concerns the design of instructional tasks while 4C/ID concerns the design of courses or whole curricula.

An interesting new opportunity arose when I joined the field of health professions education in 2009. John and I introduced CLT in an article that was published in the journal Medical Education (van Merriënboer \& Sweller, 2010). Since then, CLT quickly became popular in health professions education, especially in the subfield of medical simulation. Here, complex learning mainly refers to diagnostic reasoning and medical decision making in situations that are characterized by uncertainty, time stress and high cognitive load.

\section{Research focus.}

\section{What is your focus in the CLT research in the last decade?}

John: Throughout the last decade, I have continued to look at the importance of guidance in instruction and instructional design, and how evolutionary psychology changes the human cognitive architecture that underlies CLT. I also have attempted to expand CLT beyond its traditional mathematics and science focus. In my research over the last 2 years, I have placed central importance on element interactivity in CLT with Ouhao Chen and Slava Kalyuga. That emphasis has yielded recent interesting findings on the apparent contradiction between the 
worked example and generation effects. The generation effect occurs when learners asked to generate a response perform better than learners shown a response. With Wayne Leahy and Jose Hanham, I have looked at the consequences of element interactivity for the testing effect following on work led by Tamara van Gog. I also have conducted research with my French colleagues, Stephanie Roussel, Danielle Joulia and André Tricot on the negative consequences of learning a second language as an adult at the same time as attempting to learn content. Dayu Jiang, Slava Kalyuga and I have looked at the conditions under which learning to listen to a foreign language was superior to reading rather than merely listening. Very recently, with a very large number of collaborators, I have become interested in the way that working memory capacity changes after cognitive effort due to working memory resource depletion. Much of my current research effort is directed to this issue.

Fred: I have always been particularly interested in broadening CLT. With this goal in mind, Daniel Choi, Jeroen van Merriënboer, and I have extended the initial model of CLT by including the physical learning environment as an important aspect of cognitive load (2014). In addition, a major focus in my recent research is on how working memory load can be managed through body movement, such as gestures (e.g., with Wim Pouw and Tamara van Gog), and physical activity (e.g., with Myrto Mavilidi, Paul Chandler and Tony Okely). Another important topic that I am investigating with my colleagues from the University of Wollongong (Shirley Agostinho, Sharon Tindall-Ford, and Paul Chandler) is related to the self- 
management of cognitive load. This is particularly important for learners to be able to deal with instructional materials that have not been designed with cognitive principles in mind. With Paul Ayres and Cris Castro-Alonso, I have a very successful research collaboration on learning from statics and animations. In addition, with Tzu-Chien Liu I collaborate on research into cognitive load effects in mobile learning environments. Finally, with a large group of collaborators I have an ongoing line of research specifically focusing on the measurement of cognitive load.

Jeroen: The major change for me in the last decade was moving away from the field of general education and educational technology to the field of health professions education. This naturally led to a new interest in complex tasks such as clinical reasoning, medical decision-making, and visual diagnosis (based on X-rays, ECGs, pathological slides, etc.). Such tasks are often characterized by uncertainty because there are many competing diagnoses. The question is then how uncertainty can be reduced. Checklists are a popular instrument in the medical field but a severe problem is that using a checklist during clinical reasoning adds to the already high cognitive load. Matt Sibbald showed that using a checklist after reaching a preliminary diagnosis, thus to reconsider a diagnosis if feeling uncertain, increases accuracy because a substantial number of incorrect diagnoses is then corrected afterwards.

Popular instructional media in medical education are animations and simulations. When animations or other dynamic visualizations are used to present 
complex procedures, learners often experience high cognitive load due to the transiency effect. Segmentation may help to deal with this effect: it splits a complex dynamic visualization in meaningful segments so that a learner may fully process one segment before continuing to the next. Another issue concerns the fidelity of simulations. Mary Dankbaar showed that a simulation-based game that was very effective for medical residents was not effective at all for medical students, probably because the high cognitive load hampered their learning.

A third theme I have been working on in the last decade is the relation between cognitive load and self-regulated or self-directed learning. I have been doing research on this for quite some time, but recently I edited together with Anique de Bruin a special issue of the journal "Learning and Instruction" with contributions aiming to bridge the gap between CLT and self-directed learning (de Bruin \& van Merriënboer, 2017). In our editorial, we propose to use the cueutilization framework as the basis for a joint research paradigm. The main idea postulated is that new instructional methods should foremost help learners identify diagnostic cues in available information that provide an accurate indication of where learners stand in relation to criterion task performance. Use of these diagnostic cues when monitoring learning will lead to better regulation of learning activities and of mental resources allocated to these activities, and thus to more effective learning and higher learning outcomes. A recurrent finding in my research group is that domain-specific skills and self-directed learning skills (e.g., self-assessment, selection of learning tasks, information literacy etc.) cannot easily 
be learned simultaneously. This raises the question how the teaching of domainspecific skills and domain-general skills can best be intertwined, a topic I discuss in the most recent edition of the book Ten Steps to Complex Learning (van Merriënboer \& Kirschner, 2018).

Finally, I have been involved in some new work dealing with the measurement of cognitive load. Adam Szulewski developed some of these measures using pupillometry and eye-tracking (e.g., in simulation training, a high gaze shift rate indicates fast situational assessment and is related with a relatively low cognitive load). Lastly, I have been working with Jimmie Leppink on questionnaires that attempt to make a distinction between the different types of load.

III. Measurement of cognitive load and mental efficiency.

What role did the measurement of cognitive load and mental efficiency play in your research?

John: I have made heavy use of the Paas scale (1992) as it is very simple to use, is highly reliable and very sensitive. You can use secondary tasks, which are fairly sensitive too, but they are much messier to use compared to the Paas scale (Paas, Van Merriënboer, \& Adam, 1994). I like to ask students "how difficult learning was" while Fred puts more emphasis on asking about "the mental effort you put in". They are both highly correlated but they can have some differences. 
For many years, people said that we should have individual measures for the various types of cognitive load. Initially, I argued that this is not possible because for this to happen, learners have to understand the differences between intrinsic and extraneous cognitive load. For example, assuming you are dealing with the worked-example effect and you ask somebody to solve a problem as well as questions that in effect require that person to determine "is this difficult because of the way it is presented or is it intrinsically difficult?". They would not be able to give you an answer if they do not already know about the worked-example effect.

When Jimmie Leppink came along with data indicating that people can make this distinction (Leppink, Paas, Van Gog, Van der Vleuten, \& Van Merriënboer, 2014) my views changed. It seemed learners could distinguish between intrinsic and extraneous cognitive load. Now I am again not so sure. While learners may be able to distinguish between intrinsic and extraneous cognitive load for some familiar instructional procedures, I doubt that they can make the same distinctions for cognitive load effects with which they are less familiar.

In the last few years, I and my $\mathrm{PhD}$ students have started using Jimmie Leppink's scales to see how they work in different situations. The results have not been encouraging because we found that students were not distinguishing between intrinsic/extraneous cognitive load. If we got differences between conditions, we got similar differences on both intrinsic and extraneous load. As a consequence of those results, I am going back to Fred's original scale. 
With respect to the timing of cognitive load measures, there are differences when measurements are used. I have always tested people's cognitive load after learning and rarely tested cognitive load after content knowledge testing. People find content tests more difficult if they have not learned much and so indirectly that is an example of cognitive load while learning. I have been primarily interested in cognitive load while learning and not after testing.

Concerning the frequency of cognitive load measurement, I normally measure cognitive load only after the instruction has finished. Sometimes, if instruction can be divided into sections, I might measure it after each section and then combine the measures. In general, if it is a short-term study (about 15-20 min of learning), then I will give learners a cognitive load test, followed by a content test.

Concluding, I used to measure mental efficiency in many experiments as many people do. We used to use this measure automatically, but I guess most of the field began to feel that what you see in the working memory measure and what you see in the content measure pretty much tells you everything you need to know, so I tend not to use efficiency measures.

Fred: The different measurement techniques are described in Paas, Tuovinen, Tabbers, and Van Gerven (2003). Our research has shown that when students are asked to rate invested mental effort only once after completing all problems in task sequences that contain both simple and complex problems, this rating is higher than the average of ratings over all tasks (Schmeck, Opfermann, Van Gog, Paas, \& Leutner, 2015; Van Gog, Kirschner, Kester, \& Paas, 2012). The data suggest that 
students may base their overall rating on the most complex problems they worked on. Furthermore, there was no difference between the mean of ratings provided immediately after each task and the rating at the end when tasks were all low in intrinsic load. On the complex (high intrinsic load) problems, the rating at the end was higher than the average of ratings provided immediately after each task. Finally, it would be interesting to investigate in future studies what the relationship between multiple ratings or single ratings is along with the learning outcomes, both in terms of test performance and in terms of effort investment on the test. One might argue that it is not so bad if multiple ratings and a single rating do not correspond, as long as both would lead to the same conclusions about differences between instructional conditions. However, as mentioned before, when measuring effort only once at the end of an instructional phase, it is impossible to determine to what extent different components of the instructional package contributed to cognitive load during learning. It might therefore be advisable to apply a rating scale multiple times during a task when it is of relatively long duration (cf. first experiment of Van Merriënboer et al., 2002; Yeo \& Neal, 2004, 2008; see also Ayres, 2006, for an application of perceived difficulty ratings during a task). Moreover, repeated ratings over time in a series of tasks or in a task of longer duration will provide information on the fluctuations in cognitive load (i.e., instantaneous load; Xie \& Salvendy, 2000).

Overall, I think that mental efficiency is very important as a dependent variable in CLT research and as a basis for intelligent task-selection algorithms. In 1993, 
Jeroen and I introduced a measure of efficiency of instructional conditions, based on test performance and mental effort invested to attain this test performance that could aid researchers and instructional designers in comparing the effects of different instructional approaches on learning. It has become widely adopted, but in an adapted form that incorporates mental effort invested in the learning phase instead of the test phase. In comparing instructional materials, the adapted measure seems most useful in situations where the aim is to reduce cognitive load during learning. However, when instruction aims to stimulate learners to invest high levels of effort in processes relevant for learning the adapted measure does not seem very suitable. When analyzing efficiency of instructional conditions, we would strongly recommend researchers to always use the original measure based on mental effort (rather than difficulty) ratings and performance scores in the test phase (Van Gog $\&$ Paas, 2008). In addition, it might also be interesting to investigate the use of the efficiency measure in longitudinal studies of learning or expertise development.

Jeroen: Measuring cognitive load relates to overall cognitive load measures where it would be good to have objective and real-time measures that can complement traditional subjective measures from the Paas' scale. But I also think that we must continue investing in the development of measures for the different types of cognitive load. I see my work with Jimmie Leppink on the development of questionnaires for measuring the different types of load as only a beginning of this line of research. 
Cognitive load always needs to be related to performance. That is the reason why efficiency and task involvement are important concepts in CLT. I have always seen these concepts as two sides of the same coin. On the one hand, learners can invest less -extraneous- cognitive load in learning and reach higher learning outcomes. This combination of lower cognitive load with higher learning outcomes is reflected in the concept of instructional efficiency. On the other hand, learners can also invest more -germane- load in learning and thanks to this germane processing reach higher learning outcomes. This latter concept is reflected in the concept of task involvement (Paas, Tuovinen, van Merriënboer, \& Darabi, 2005).

\section{The instructional control of cognitive load.}

\section{How important is the instructional control of cognitive load in CLT and}

\section{research?}

John: The instructional control of cognitive load provides the ultimate raison d'être of CLT. The theory is concerned with procedures to reduce the burden on working memory when dealing with complex (high element interactivity) novel information to facilitate the transfer of knowledge to long-term memory. The success of the theory should be gaged by the extent to which it meets this aim.

Fred: Not surprisingly, given the central tenet of CLT, the aim of researchers in the field of CLT has been to engineer the instructional control of cognitive load to provide the means to optimize cognitive load in learning arrangements. It was 
proposed that initially, the element interactivity of complex material had to be artificially reduced to enable a schema or partial schema for the information to be developed. That reduction could be accomplished by presenting the material as isolated elements that could be processed in working memory. The consequence of the reduction in element interactivity of material may result in an initial decrease in the student's capacity for understanding. Over the longer-term however, it was hypothesized that the promotion of schema construction would lead to an increase in the learner's understanding. Although extraneous load does not have a significant negative impact on learning when tasks are low in intrinsic load, it does so when tasks are high in intrinsic load. Therefore, reducing extraneous load is considered imperative for such tasks. Examples of extraneous load reducing measures are using integrated text and diagram formats instead of split-source formats (split-attention effect; e.g., Chandler \& Sweller, 1991), avoiding presentation of redundant information (redundancy effect; e.g., Chandler \& Sweller, 1991), and making use of multiple modalities to present mutually referring textual and pictorial information (modality effect; e.g., Mousavi, Low, \& Sweller, 1995). When extraneous load is lowered, learners may have cognitive capacity left that can be invested in processes that impose a germane load, that is, which do contribute to learning. However, they are unlikely to engage in such activities spontaneously. Examples of germane load-inducing measures are imagination or self-explanation assignments to process the solution steps in worked examples more deeply (e.g., Atkinson, Renkl, \& Merrill, 2003; Cooper, Tindall-Ford, 
Chandler, \& Sweller, 2001) and study assignments of high-variability sequences of worked examples (e.g., Paas \& Van Merriënboer, 1994a).

Jeroen: CLT suggests many principles for managing cognitive load, but on the level of course and curriculum design for the acquisition of complex skills my 4C/ID model stresses the utmost importance of three interrelated principles (van Merriënboer, Clark, \& de Croock, 2002). First, complex skills impose a very high intrinsic cognitive load on novice learners. Therefore, it is necessary to build a sequence of simple-to-complex task levels so that learners can first practice very simple versions of a task, and then practice tasks on increasingly more complex levels until they reach the final attainment level of a course or program (i.e., a spiral approach to teaching). Second, when learners start to work on tasks on a new, higher level of complexity, unguided problem solving will typically impose a very high extraneous cognitive load (van Merriënboer, 2013). Therefore, it is necessary to provide support and guidance to learners and to gradually decrease this support and guidance in a process of "scaffolding". One very powerful approach to scaffolding is the completion strategy: first have the learners study worked examples, then have them complete increasingly larger parts of partially given problem solutions, and finally have them independently generate full solutions. Third, learners must be stimulated to invest in learning processes that yield a germane cognitive load, in particular, processes that help them to generalise and abstract away from single learning tasks. Variability of practice is a particularly strong method to stimulate learners' germane processing. 


\section{Upgrade of CLT.}

\section{In your opinion, what are the most important recent updates of CLT?}

John: Geary’s distinction between biologically primary and secondary knowledge has greatly contributed, extended and developed CLT in recent years. His work is quite central to human cognitive architecture (Geary \& Berch, 2016)- It is critically important to use biologically primary knowledge (because it is so much easier) to assist people in acquiring biologically secondary knowledge. For example, if you tell somebody to self-evaluate or self-monitor, which is biologically primary, they know how to do it. But they may not know that it is important at a particular time on a particular task. You can transform their performance by pointing out to them when biologically primary knowledge is important when dealing with a biologically secondary task.

Other examples are gestures and their effects on learning. If you inhibit people from gesturing, their thought processes are inhibited. We can assume that from an evolutionary perspective, we would have learned to communicate with gestures prior to learning to communicate by speech. When speech came along, it probably did not replace gestures, it just added to gestures, which were always there and have never gone away.

Fred: As for the upgrades of CLT, we began to focus on the role of the physical environment during learning. Until recently, the specific characteristics of the physical learning environment that could affect cognitive load have not been 
considered important. The central issue of our research is not only the casual interaction between the physical learning environment and the characteristics of learners and learning tasks, but also to test whether the specific physical learning environment can be regarded as cognitively efficient if a higher performance is attained with a lower invested mental effort by adopting the concept of the learning efficiency. Interestingly, the identification of the physical learning environment as a causal factor of cognitive load may also shed new light on the concept of germane load. The newer conception of germane load is typically believed to increase intrinsic load by adding interactive elements (e.g., from long-term memory or the context) to working memory. If it is true that the physical environment can also impose a germane cognitive load, for example by introducing a moderate level of noise (Mehta, Zhu, \& Cheema, 2012), this new conceptualization of germane load might need to be reconsidered, because it seems unlikely that noise increases the number of interacting elements in working memory.

Jeroen: Much more research needs to be conducted before we can reach a final judgment on the eventual impact of the "upgrades" of CLT on the theory. Geary's distinction is straightforward and has important implications for teaching, but it is also becoming clearer that complex skills such as information literacy and selfdirected learning rely on an inextricable mix of primary and secondary knowledge. It is yet unclear how instructional design principles should deal with this mix. A similar point can be made with regard to the effects of the physical environment on cognitive load. It may, for example, explain how characteristics 
of the environment causing stress, emotions or uncertainty have an impact on cognitive load, but underlying mechanisms and implications for instructional design are still largely unknown.

In addition to "upgrades" of CLT, I think that "extensions" to particular fields of application are at least as important. So far, well-known examples are applications in the field of multimedia design, where the cognitive theory of multimedia learning includes many design principles from CLT, and course and curriculum design, where my own 4C/ID model aims to be consistent with CLT. It would be good to develop similar models for application domains such as workplace learning in the professions or blended learning.

\section{Inspirations.}

\section{What is your advice for junior researchers to become successful in research?}

John: Many of the most influential effects of CLT have been discovered by accident. Anything that surprises you is likely to be important. If it surprises you, it means that it is new. If you look at a set of results and get exactly what you were expecting, you may need to consider whether it is important. But, if you look and find it surprising and do not know why you obtained that result, it could be very important. A good researcher in this field is a good researcher in any scientific field. Good researchers take note of data and use theories that could be falsified. If you are using theories that can never be falsified, or use theories that ignore the data, then there is a problem with the theories. 
In CLT, we have been wrong on numerous occasions. The reason why CLT is so successful is precisely because we have got it wrong at times and developed the theory as a consequence. Developing new cognitive load effects has often occurred after failed experiments. If you are running a research program whose research cannot fail, what is the point of doing it? Data is central to scientific research. If you cannot organise research which throws up data and suggests you may be wrong, there is no progress. Every theory is an approximation to reality. We hope that as theories change we get closer and closer to reality. We never get there, we are just getting closer!

Fred: I am convinced that the only way to become a successful researcher is to invest a lot of time. Knowing that you have to do this it seems obvious that you should follow your passion and curiosity when choosing a research topic. In addition, such a topic should have important theoretical and educational implications. A lot of time should be invested in reading high-quality articles, discussing your work with peers and experts, review articles of other colleagues, present your work at international conferences, and talking to productive researchers. I am seldomly inspired by research within my own field, and all my 'new' ideas for new CLT developments were inspired by reading a lot of articles outside my own discipline. So, I am also a strong believer in the borrowing and reorganisation principle; most of the knowledge that we acquire comes from the longterm memories of other people, or more specifically, from the articles that other researchers have published. 
Finally, another important point relates to being respectful of past research and giving credit to the foundational authors. I have seen many young researchers who think that they can become successful by proving that experts in the field are wrong. I think that it is highly unproductive to try to advance your own career by denigrating the contributions of others.

Jeroen: As Confucius said: "Choose a job you love, and you will never have to work a day in your life". If being a researcher is the right job for you, just go with the flow and have fun, all the rest will follow naturally.

\section{References}

Atkinson, R. K., Renkl, A., \& Merrill, M. M. (2003). Transitioning from studying examples to solving problems: Effects of self-explanation prompts and fading worked-out steps. Journal of Educational Psychology, 95(4), 774-783.

Ayres, P. (2006). Using subjective measures to detect variations of intrinsic cognitive load within problems. Learning and Instruction, 16(5), 389-400.

Chandler, P., \& Sweller, J. (1991). Cognitive load theory and the format of instruction. Cognition and Instruction, 8(4), 293-332. 
Chen, O., Castro-Alonso, J. C., Paas, F., \& Sweller, J. (2017). Extending cognitive load theory to incorporate working memory resource depletion: Evidence from the spacing effect. Educational Psychology Review, 30(2), 483-501.

Choi, H. H., Van Merriënboer, J. J., \& Paas, F. (2014). Effects of the physical environment on cognitive load and learning: towards a new model of cognitive load. Educational Psychology Review, 26(2), 225-244.

Cooper, G., Tindall-Ford, S., Chandler, P., \& Sweller, J. (2001). Learning by imagining. Journal of Experimental Psychology: Applied, 7(1), 68-82.

De Bruin, A. B. H., \& van Merriënboer, J. J. G. (2017). Bridging cognitive load and self-regulated learning research: A complementary approach to contemporary issues in educational research. Learning and Instruction, 51, 1-9.

Geary, D., \& Berch, D. (2016). Evolution and children's cognitive and academic development. In D. Geary \& D. Berch (Eds.), Evolutionary perspectives on child development and education (pp. 217-249). Switzerland: Springer.

Leppink, J., Paas, F., Van Gog, T., Van der Vleuten, C. P. M., \& Van Merrienboer, J. J. G. (2014). Effects of pairs of problems and examples on task performance and different types of cognitive load. Learning and Instruction, 30, 32-42.

Mehta, R., Zhu, R., \& Cheema, A. (2012). Is noise always bad? Exploring the effects of ambient noise on creative cognition. Journal of Consumer Research, 39(4), 784-799. 
Mousavi, S. Y., Low, R., \& Sweller, J. (1995). Reducing cognitive load by mixing auditory and visual presentation modes. Journal of Educational Psychology, 87(2), 319-334.

Paas, F. (1992). Training strategies for attaining transfer of problem-solving skill in statistics: A cognitive-load approach. Journal of Educational Psychology, 84(4), 429-434.

Paas, F., Camp, G., \& Rikers, R. (2001). Instructional compensation for age-related cognitive declines: Effects of goal specificity in maze learning. Journal of Educational Psychology, 93(1), 181-186.

Paas, F., Tuovinen, J. E., van Merriënboer, J. J. G., \& Darabi, A. (2005). A motivational perspective on the relation between mental effort and performance: Optimizing learner involvement in instruction. Educational Technology, Research and Development, 53(3), 25-34.

Paas, F., \& Van Merriënboer, J. J. G. (1994). Variability of worked examples and transfer of geometrical problem-solving skills: A cognitive-load approach. Journal of Educational Psychology, 86, 122-133.

Paas, F., Van Merriënboer, J. J., \& Adam, J. J. (1994). Measurement of cognitive load in instructional research. Perceptual and Motor Skills, 79(1), 419-430.

Schmeck, A., Opfermann, M., van Gog, T., Paas, F., \& Leutner, D. (2015). Measuring cognitive load with subjective rating scales during problem solving: differences between immediate and delayed ratings. Instructional Science, 43(1), 93-114. 
Sweller, J., \& Cooper, G. A. (1985). The use of worked examples as a substitute for problem solving in learning algebra. Cognition and instruction, 2(1), 59-89.

Van Gog, T., Kirschner, F., Kester, L., \& Paas, F. (2012). Timing and frequency of mental effort measurement: Evidence in favour of repeated measures. Applied Cognitive Psychology, 26(6), 833-839.

Van Gog, T., \& Paas, F. (2008). Instructional efficiency: Revisiting the original construct in educational research. Educational Psychologist, 43(1), 16-26.

Van Merriënboer, J. J. G. (1997). Training complex cognitive skills. Englewood Cliffs, NJ: Educational Technology Publications.

Van Merriënboer, J. J. G. (1990). Strategies for programming instruction in high school: Program completion vs. program generation. Journal of Educational Computing Research, 6, 265-285.

Van Merriënboer, J. J. G. (2013). Perspectives on problem solving and instruction. Computers and Education, 64, 153-160.

Van Merriënboer, J. J. G., Clark, R. E., \& de Croock, M. B. M. (2002). Blueprints for complex learning: The 4C/ID-model. Educational Technology, Research and Development, 50(2), 39-64.

Van Merriënboer, J. J. G., \& de Croock, M. B. M. (1992). Strategies for computerbased programming instruction: Program completion vs. program generation. Journal of Educational Computing Research, 8, 365-394. 
Van Merriënboer, J. J. G., Jelsma, O., \& Paas, F. (1992). Training for reflective expertise: A four-component instructional design model for complex cognitive skills. Educational Technology, Research and Development, 40(2), 23-43.

Van Merriënboer, J. J. G., \& Kirschner, P. A. (2018). Ten steps to complex learning (3rd Rev. Ed.). New York: Routledge.

Van Merriënboer, J. J. G., \& Krammer, H. P. M. (1987). Instructional strategies and tactics for the design of introductory computer programming courses in high school. Instructional Science, 16, 251-285.

Van Merriënboer, J. J. G., \& Sweller, J. (2010). Cognitive load theory in health professional education: Design principles and strategies. Medical Education, 44(1), 85-93.

Xie, B., \& Salvendy, G. (2000). Review and reappraisal of modelling and predicting mental workload in single-and multi-task environments. Work \& Stress, 14(1), 74-99.

Yeo, G. B., \& Neal, A. (2004). A multilevel analysis of effort, practice, and performance: effects; of ability, conscientiousness, and goal orientation. Journal of Applied Psychology, 89(2), 231-247.

Yeo, G., \& Neal, A. (2008). Subjective cognitive effort: a model of states, traits, and time. Journal of Applied Psychology, 93(3), 617-631. 
